\title{
Who Has Published What in East Asian Studies?
}

\section{An Analysis of Publishers and Publishing Trends}

\section{By Su Chen and Chengzhi Wang}

This study examines Western-language, particularly English-language, monographs on East Asian studies published in the United States, Canada, England, Australia, and other countries from 2000 through 2005. The study provides a landscape view of the scope and trends of publications for both scholars and librarians in East Asian studies. The data for this study were collected from the YBP's GOBI (Global Online Bibliographic Information) database, covering publications profiled by YBP from January 1, 2000, through December 31, 2005. The results of data analysis shed light on scholarly currents and publishing trends in East Asian studies over that six-year period.

Su Chen (suchen@umn.edu) is Head of the East Asian Library, University of Minnesota Libraries, Minneapolis; Chengzhi Wang (cw2165@columbia edu) is Chinese Studies Librarian, C. V. Starr East Asian Library, Columbia University, New York.

The authors wish to thank Marcia Pankake for her inspiration to write the article and her invaluable advice and comments during the writing. Her guidance and help are greatly appreciated. The authors are indebted to Bob Nardini and Carolyn Morris, Bibliographers at YBP for helping with data collection and proofreading drafts. The authors are grateful to Peggy Johnson and her anonymous reviewers for their helpful advice and comments for revision. The authors thank Barbara Davis for her editing of the final draft.

Submitted January 26, 2007; tentatively accepted pending revision March 15 , 2007; revised and resubmitted May 2, 2007, and accepted for publication.
Scholars and librarians in East Asian studies often wonder how research productivity and publishing trends evolve in the field. Which publishers are active in this field? What subject areas have been covered prolifically or meagerly, and what does the publishing landscape look like? Traditionally, the areas of East Asian literature, history, and philosophy have been strongly represented. Is this still so? Have traditional trends experienced any shifts? Which publishers are the major players in the field? Do university presses publish in different areas from commercial publishers?

Some fifty years ago, Frederick Mote (1922-2005), a leading professor of Chinese history and culture at Princeton University, raised similar questions. He surveyed important academic publishers and their major publications, introducing new publishing developments in Chinese studies in the Republic of China on Taiwan to the Journal of Asian Studies audience. ${ }^{1}$ He wrote, "Although the Journal has on several occasions during the last five or six years reported briefly on publication there, now there is perhaps some value in reporting more comprehensively on recent developments, both because the phenomenon itself is of interest, and because many recently published items will be desired by scholars and by research libraries." The authors of this article share his rationale in the examination of recent scholarly currents and publishing trends.

The purpose of Mote's survey was "not to list all of the worthwhile books recently published, for that would be an obvious impossibility, but to make the general outlines and character of recent publication activities known, and to inform the reader of names and addresses of publishers from whom more detailed information can be obtained."3 Today, however, improved technology can be utilized to achieve the goal of a fairly complete survey. Technologically, all 
worthwhile books recently published can be listed and analyzed. The authors used YBP's Global Online Bibliographical Information (GOBI) database in hopes of providing a comprehensive analysis of nearly all publications profiled. The analysis helped reveal characteristics of these publications and East Asian studies publishing trends.

This study's purpose was to evaluate the scope of, and trends in, East Asian research and publications. In the study, the authors use the term "East Asian studies" to refer to studies on China, Japan, and Korea; "Chinese studies" includes People's Republic of China, Taiwan, Hong Kong, Macao, and Tibet. Within "Korean studies," both North Korea and South Korea are covered. In this study, the focus is on print books. The scope includes English-language monographs on East Asian studies published in the United States, Canada, England, Australia, and other countries between 2000 and 2005. The data were collected from GOBI, covering publications profiled by YBP from January 1, 2000, through December 31, 2005.

Research and publishing trends are of interest to publishers, though largely from the perspective of sales. The Association of American Publishers Industry Statistics Annual Report registers data based on publishers' responses to questionnaires, collecting data on the sale of books in the category of "Professional and Scholarly Publishing," which covers categories of technical, scientific, law, business, humanities, and medical materials. ${ }^{4}$ However, data and information on publications pertaining to Asian studies or East Asian studies are not readily available.

Research and publishing trends also are of interest to governmental and nongovernmental organizations. For instance, the Tokyo-based Centre for East Asian Cultural Studies for UNESCO (1961-2003) published the annual Asian Research Trends: A Humanities and Social Science Review from 1991 through $2003 .{ }^{5}$ After a hiatus of a few years, the annual was continued by Toyo Bunko in 2006 . This annual publication provided useful information on the history and trends in research topics on both macro and micro levels in Asian studies, particularly in East Asian studies, and in various countries and regions. The Ford Foundation sponsored the editing and publishing of such bibliographies on Asian studies as India and America: American Publishing on India, 1930-1985, which traced the historical development of American publishing on Indian studies. ${ }^{6}$ The Japan Foundation has had multiple initiatives to introduce new publications and help library collection development. Its Japanese Book News often has included articles on publishing trends on Japan since 1993. ${ }^{7}$ With sponsorship from the Japan Foundation and others, the North American Coordinating Council on Japanese Library Resources (NCC) is known for facilitating collection development and resource sharing on Japanese studies.
Scholarly and publishing trends always are of interest to scholars and librarians. Numerous monographs, journals, journal articles, special issues of journals, and conferences proceedings have been devoted to the study of East Asian studies, particularly country-specific studies. For example, Hardacre analyzed the postwar development of Japanese studies in the United States in various subject areas. ${ }^{8}$ The Taiwan-based journal Issues \& Studies: An International Quarterly on China, Taiwan and East Asian Affairs published a special issue, "The State of the China Studies Field," edited by Marble. ${ }^{9}$ In addition to articles on various subject areas of Chinese studies, the special issue also included commentaries from editors of five leading journals that represented the state of scholarly journals in this field. Furthermore, it contained a useful bibliographical appendix of articles on the state of the China studies field. For Korean studies, the conference on the "Future of Korean Studies in the United States" was held at the University of California, Berkeley, in 2001 with the support of the Korean Foundation. $^{10}$

\section{Literature Review}

The authors searched general and subject databases for literature related to trends in scholarly publications on East Asian studies; however, the data were unexpectedly scarce. Publications with comprehensive data and analyses were especially limited. Articles by both scholars and librarians who sought to survey, review, and analyze the state of the scholarship development, did, however, examine the trends of publishing on East Asian studies as part of their research.

Mote's 1958 survey of leading publishers and their major publications in Taiwan in 1954-1955 was of great benefit to scholars and librarians because it outlined and characterized recent relevant publications of major publishers and listed contact names and addresses for these publishers. ${ }^{11}$ Soong discussed the most recent developments in Chinese publishing by examining the five issues of the Chiuan-kuo hsin shu-mu (The National Bibliography) published in 1973, identifying and introducing a number of new important works. ${ }^{12}$ It was informative and insightful, especially during the Culture Revolution (1966-1976), when information on Chinese publications was scare, but the article was based on data from only five issues of the monthly, and only a small number of books published were of long-term academic value.

The Committee on East Asian Libraries Executive Group of the Association of Asian Studies issued a report on current trends as part of an Association of Research Libraries project titled "Scholarship, Research Libraries and Foreign Publishing." ${ }^{.33}$ This general report estimated current trends 
of East Asian publishing along with extensive availability of electronic resources, described historical and current collecting patterns, analyzed library response to price trends, and gauged trends of scholarly research. However, "the report does not attempt in-depth analysis and at best provides only a sketchy picture of the complex array of problems facing East Asian studies librarians in these rapidly changing times." 14 Though the information in the article on East Asian library collections was presented with adequate statistical data from individual East Asian libraries, the publishing trends in East Asia were not supported with detailed data and information, and the trends of the English-language publishing in the world, particularly North America, were not mentioned.

Blum's 2002 book review covered seven books on Chinese ethnic minorities and attempted to trace a decade of publishing about China's ethnic minorities. ${ }^{15}$ It analyzed scholarly trends, guiding topics, and theoretical debates in the field of Chinese ethnic studies from the 1990s. Blum examined and analyzed a large number of works on ethnic minorities in order to present major research themes and publication trends. Despite the lack of detailed statistical data, Blum, as with Mote, offered one of the few publications of in-depth analysis of research trends.

Shulman provided an interesting and useful annotated bibliography of books and doctoral dissertations on library and information science related to East Asia completed or published between 1999 and 2004. ${ }^{16}$ He did not indicate, however, how he collected the data, simply reporting that he called for authors and librarians to submit information. Without more systematic data collection, he may have left out some relevant titles.

Leung, Chan, and Song examined the publishing trends in Chinese medicine and related subjects via search and analysis of records documented in OCLC's WorldCat. Their study aimed to give an overview of how Chinese medicine had been interpreted and presented to the non-Chinese world, and to identify emerging trends. They analyzed the publishing trends in Chinese medicine and related subjects in all languages except Chinese, ranging from books and serials to audio-visual and electronic resources from the past thirty years. Their findings showed publications in Chinese medicine and related subjects flourished from the 1970s, and materials in English constituted the major portion of total output. This study is notable, as it is one of the few to comprehensively examine publishing trends in one subject area by utilizing the online search technologies of a very large bibliographic database. However, as with the Committee on East Asian Libraries Executive Group of the Association of Asian Studies, the data collected were library records that focused on collection development rather than publishing trends. ${ }^{17}$

A considerable amount of literature has sought to examine the state of scholarship, research currents, and publishing trends related to East Asian studies, particularly country-specific studies. The literature is conducive to a better understanding of the development of East Asian studies scholarship and librarianship. Yet a systematic, comprehensive examination and analysis of publishing trends in East Asian studies and the specific countries and regions has been lacking.

Of the literature examined, only Leung, Chan, and Song collected comprehensive, quantitative data. Most of the literature offered no more than general observation or sketchy impressions of publishing trends in East Asian studies. With the help of distributed information technology, the authors aimed to gather more comprehensive quantitative data and present their analysis of publishing trends of East Asian studies.

\section{Research Method: A Different Approach for Gauging Publishing Trends in East Asian Studies}

YBP is one of the largest academic book distributors in North America and served as the source of data. The data used in this study were collected on June 14, 2006, from GOBI, YBP's proprietary database. At that time, the database contained approximately 3 million English-language titles published worldwide, including publications from more than 40,000 publishers outside Europe; from 6,300 European publishers listed by Lindsay \& Croft, a United Kingdom-based YBP subsidiary focusing on the United Kingdom; and from other European academic book supply and library services.

Every year, YBP profiles approximately 55,000 new titles published by 1,800 publishers (about 1,100 titles every week), adding the resulting bibliographic detail to GOBI. ${ }^{\text {is }}$ Profiling refers to selecting and describing books that match academic libraries' profiles, or collecting interests, as outlined by collection development librarians. The profiled books contain detailed bibliographic and imprint information as well as YBP subjects and geographical descriptors added book-in-hand by YBP bibliographers. YBP practice also is guided by cataloging rules and such tools as AACR2 (Anglo-American Cataloguing Rules, 2nd ed.); Library of Congress classification schedule; and Library of Congress subject headings, including geographical headings applied to profiled books. These features permit online search functions similar to those of most online public access catalogs (OPACs). In addition, some unique features, such as profiling dates, are available.

Most of the English-language monographs profiled by YBP are searchable online in GOBI. They have been published in the United States, Canada, England, Hong Kong, or Australia. Other countries and regions are less represented. Publications by associations and societies, such 
as the Association for Asian Studies, are not necessarily profiled by YBP or included in GOBI. Overall, the publishers excluded from the database constitute a relatively small portion of the total. The database covers approximately 90 percent of the publishers of English-language materials on East Asian studies. YBP updates its publisher coverage on a regular basis.

In order to retrieve the publications on East Asian studies, the following search criteria were used:

- Publishing dates: 2000 through 2005.

- Profiling dates: January 1, 2000 through December 31, 2005.

- Scope: Publishers covered by YBP and Lindsay \& Croft.

- Content level (these categories are assigned by YBP): general academic, advanced academic, popular, and professional; the juvenile category was excluded.

- Geographical descriptors: China, Japan, Korea, Hong Kong, Taiwan, Macao, and Tibet. Because Tibet is treated as an individual entity in GOBI, apart from China, Tibet was used as the geographical descriptor to capture the relevant data on Tibet.

- Title count: The same title by the same author published simultaneously in the United States and the United Kingdom was counted as one title. Hardcover and paperback editions for the same title by the same author also were counted as one title.

Additionally, search result quality control was maintained by repeating the search at different times and comparing results. The same search strategy with identical criteria was repeated in May and June 2006 to see if the retrieved data differed. The numbers of hits were found to be consistent on five separate occasions. The repetition of searches and the comparison of results were conducted to ensure the reliability of both the criteria defined and the method applied. Such criteria and method may be applied for examining other subject areas.

\section{Findings: Who Has Published What?}

This study resulted in interesting findings on publishing trends, particularly output of publications, distribution of output with publishers, and representation of subject areas over the years. The total number of published monographs listed in GOBI on East Asian studies from 2000 through 2005 was 4,924, of which 2,710 monographs were on China, 1,854 on Japan, and 360 on Korea (see table 1). China remained the major focus of scholarly interest in the period of study, accounting for more than half of the published monographs each year. During these six years, the aggregated number of monographs on China was about 1.46 times as many as those on Japan, and 7.52 times as many as those on Korea.

From 2000 through 2005, publishing on East Asian studies as a whole experienced significant growth - the total number of published monographs increased from 633 in 2000 , to 928 in 2005 . However, publishing in each of the three areas-China, Japan, and Korea-experienced dips in different years during the period. As shown in figure 1, Japanese studies experienced nearly the same decline in 2003 and 2004, but recovered in 2005, surpassing its 2002 total. For Chinese studies, the decline existed in 2005, with 488 monographs compared to 522 in 2004 . For Korean studies, the dip occurred in 2004, with 47 monographs published, compared to 66 produced one year earlier. The year 2005 was a very productive one for Korean studies, with 84 monographs produced, almost double the output of 2000.

Publishers with an output of 10 or more monographs accounted for nearly half of the total output of monographs on East Asian studies. In 2005, 22 (of 325) publishers published 10 or more monographs (see table 2). Among the 22 publishers, 10 are university presses; their total output was

Table 1. Number of monographs published on China, Japan, and Korea, 2000-2005

\begin{tabular}{lcccc}
\hline Years & Total & China & Japan & Korean \\
2005 & 928 & 488 & 356 & 84 \\
2004 & 876 & 522 & 307 & 47 \\
2003 & 843 & 474 & 303 & 66 \\
2002 & 873 & 475 & 335 & 63 \\
2001 & 771 & 396 & 320 & 55 \\
2000 & 633 & 355 & 233 & 45 \\
Total & $\mathbf{4 , 9 2 4}$ & $\mathbf{2 , 7 1 0}$ & $\mathbf{1 , 8 5 4}$ & $\mathbf{3 6 0}$ \\
\hline
\end{tabular}

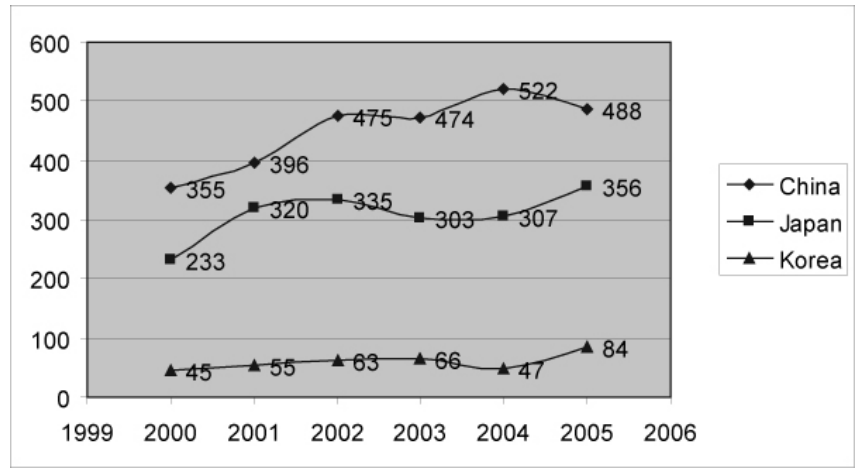

Figure 1. Number of monographs published on China, Japan, and Korea, 2000-2005 
174. Of the rest, 12 commercial publishers produced 229 monographs. In terms of productivity, commercial presses were more productive and active than their counterparts in the academic world. On an average, commercial publishers produced 19 titles, while university presses only produced 8 books.

During the six years, an increasing number of publishers began publishing monographs on East Asian studies. In 2000, 217 publishers were printing monographs on East Asian studies, only 14 of whom produced 10 or more. In 2005 , the number of publishers increased to 325 (108 more than in 2000), and the number of publishers producing 10 or more monographs jumped to 22 .

Among university presses, the University of Hawaii Press was a leading publisher during the six years, producing 183 books total and about 30 books per year. Oxford

Table 2. Publishers producing ten or more titles in 2005

\begin{tabular}{|c|c|c|c|c|}
\hline Publishers & China & Japan & Korea & Total \\
\hline Routledge & 25 & 12 & 2 & 39 \\
\hline University of Hawai'i Press & 14 & 16 & 7 & 37 \\
\hline RoutledgeCurzon & 15 & 15 & 0 & 30 \\
\hline Hong Kong University Press & 24 & 2 & 0 & 26 \\
\hline Palgrave Macmillan & 13 & 13 & 0 & 26 \\
\hline Tuttle Publishing & 1 & 22 & 1 & 24 \\
\hline Stanford University Press & 19 & 2 & 1 & 22 \\
\hline Brill & 17 & 1 & 0 & 18 \\
\hline Columbia University Press & 12 & 5 & 1 & 18 \\
\hline Global Oriental & 0 & 11 & 7 & 18 \\
\hline Kodansha & 0 & 16 & 0 & 16 \\
\hline Chinese University Press & 14 & 0 & 0 & 14 \\
\hline $\begin{array}{l}\text { Harvard University } \\
\text { Asia Center }\end{array}$ & 7 & 7 & 0 & 14 \\
\hline Marshall Cavendish Academic & 12 & 1 & 0 & 13 \\
\hline Edwin Mellen & 11 & 1 & 0 & 12 \\
\hline Rowman \& Littlefield & 10 & 2 & 0 & 12 \\
\hline University Press of America & 4 & 2 & 6 & 12 \\
\hline Oxford University Press & 6 & 3 & 1 & 11 \\
\hline $\begin{array}{l}\text { University of Washington } \\
\text { Press }\end{array}$ & 7 & 4 & 0 & 11 \\
\hline Cambridge University Press & 4 & 6 & 0 & 10 \\
\hline Hotei Publishing & 0 & 10 & 0 & 10 \\
\hline Kegan Paul International & 1 & 8 & 1 & 10 \\
\hline Total & 216 & 159 & 27 & 403 \\
\hline
\end{tabular}

University Press gradually reduced its output over the years to only 11 titles in 2005, compared to 31 in 2000 . RoutledgeCurzon and Routledge were leaders among commercial publishers since 2000; Routledge produced a total of 154 books over the past six years. After Routledge and Curzon joined forces in 2003, RouteldgeCurzon had a total output of 164 monographs-about 55 books per year for 2003 through 2006. Some publishers, such as M. E. Sharp, published much less in 2003 and 2004, and printed only 6 monographs in 2005. In contrast, Global Oriental, a newly emerging commercial publisher, occupied a spot among the top ten in the changed publishing landscape of 2005.

In terms of country-specific analysis, publishers seem to have reshaped the boundaries of their coverage, especially in newly emerged fields within East Asian studies. Global Oriental focused exclusively on Japan and Korea (see table 2), Kodansha focused on various subjects of Japan, and Hotei focused its attention solely on Japanese arts. Chinese University Press, conversely, focused solely on China in 2005 , unlike in previous years, when it printed a few titles on Japan.

A variety of subject areas were represented, except for general works (that is, collections, series, collected works, encyclopedias, dictionaries and other general reference works, indexes, museums, newspapers, periodicals, academies and learned societies, yearbooks, almanac, directories, histories of scholarship and learning, the humanities). Only 1 title described as general works on China was published in 2004 .

The published monographs were unevenly distributed across subject areas. Overall, history, language and literature, and fine arts continued to grow and dominate the publishing landscape (see appendix). The aggregated numbers of monographs published on these three subject areas increased from 157, 96, and 48 in 2000, to 191, 189, and 128 in 2005, respectively. The increased output on history in 2005 was 34 titles more than in 2000 . The increase in literature was more notable, with 189 in 2005, doubling the 2000 output of 96 . The biggest increase was in fine arts; the total output of 128 in 2005 was almost three times the total titles (48) produced in 2000. Activities in social sciences increased, with the total number of published monographs increasing from 159 in 2000, to 177 in 2005. Titles in social sciences, containing disciplines of economics, commerce, finance, and sociology, had outnumbered the fine arts. Auxiliary sciences of history, ethnic, music, medicine, agriculture, naval science, and bibliography were low in 2000 and remained low in 2005. The number of monographs on geography, anthropology, philosophy and religion, technology, and military science was higher, while the total number of monographs on political science experienced a slight decline, from 34 in 2000, to 24 in 2005. Law and education experienced erratic changes over the years. 
The output of published monographs was not evenly distributed in terms of country coverage. In most years, the numbers of monographs on various subject areas pertaining to China are larger than those pertaining to Japan, except for in agriculture and technology. Over the six years, a total of 34 monographs on agriculture and 111 monographs on technology pertaining to Japan were published. See tables 3 and 4 .

Special mention should be made about the publishing trends represented by the monographs and their subject areas from the leading presses, such as the University of Hawaii Press and Routledge. Over the six years, the University of Hawaii Press published a total of 184 monographs, of which 82 were on China, 81 on Japan, and 21 on Korea. Routledge produced a total of 148 titles, of which 73 were on China, 62 on Japan, and 13 on Korea. Similar to the trend of the larger publishing world discussed above, both experienced increases in monographs over the years, yet the increase was far from linear, with up-and-down changes over the period. The concentrations of subject areas also were similar to that of the larger publishing world. Over the study's years, the University of Hawaii Press focused on language and literature, with 23 titles published on China, 25 titles on Japan, and 7 titles on Korea. In religion and philosophy, the University of Hawaii Press published a total of 21 titles on China, 13 titles on Japan, and 2 titles on Korea. East Asian history and fine arts was the third largest subject area concentration, with nearly identical numbers of monographs on China and Japan.

Sharing the general trends of the larger publishing world, Routledge, however, was much different from the University of Hawaii Press, particularly in terms of subject area concentrations. Over the years, Routledge's primary

Table 3. Subjects areas that University of Hawaii Press published on China, Japan, and Korea 2000-2005

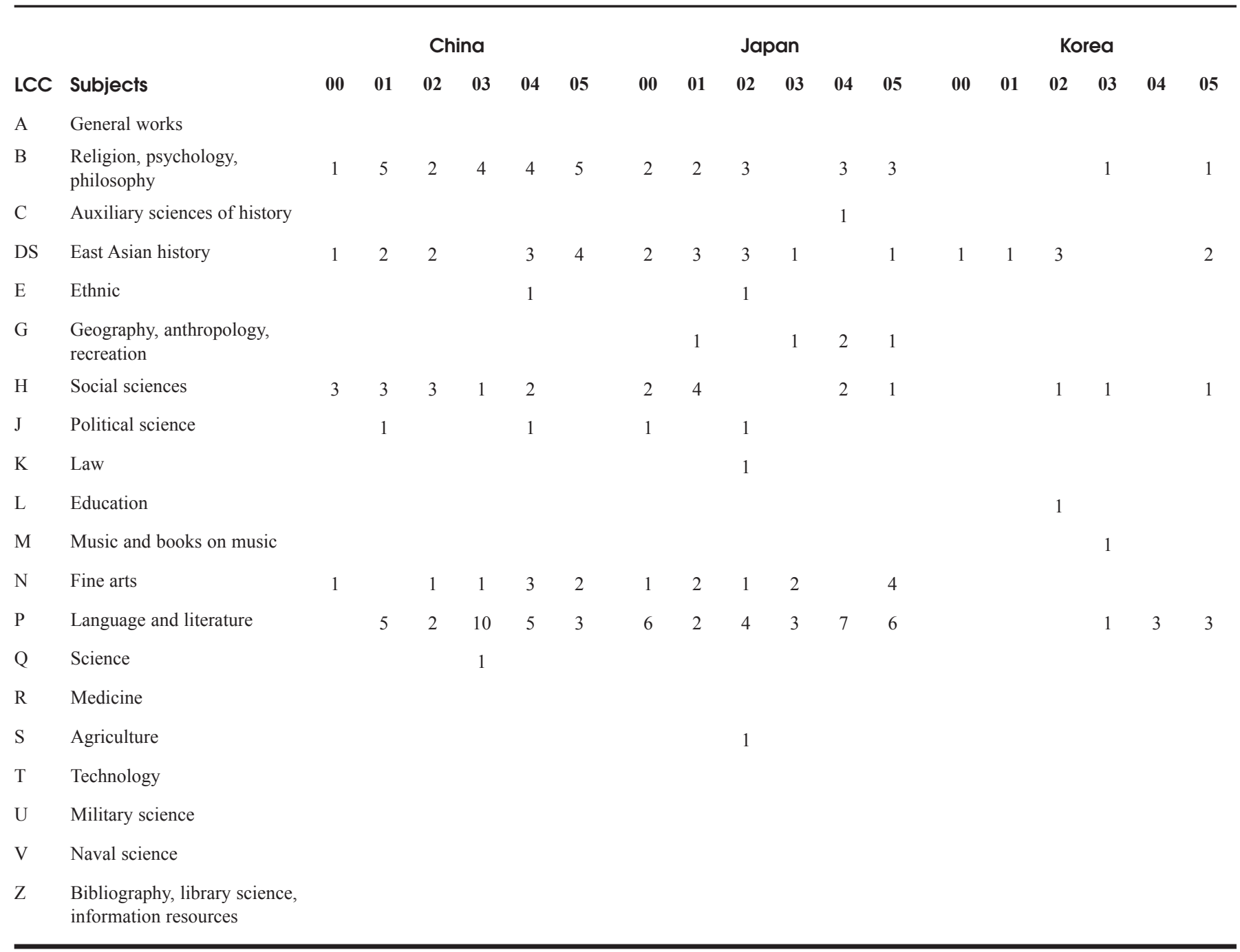


emphasis was on the social sciences, with 32 titles published on China, 22 titles on Japan, and 7 titles on Korea. Next was East Asian history, with a total of 17 titles on China, 16 titles on Japan, and 2 titles on Korea. Political science followed as the third largest area of focus, with 9 monographs printed on China, 6 on Japan, and 2 on Korea. Unlike the University of Hawaii Press, Routledge had only 1 title on fine arts over the years.

As noted previously, Tibet is included in Chinese studies. The field of Tibetan studies has received increasing attention, thus publishing in this area warrants closer review. The roots of Tibetan scholarship in the United States can be traced back to the 1960s, when federal funding and countless shipments of Tibetan texts from India fueled new programs at such research universities as Columbia, Harvard, and Indiana - often in departments of religion or Sanskrit studies. In addition, the Tibetan Buddhist Learning Center based in Washington, New Jersey, produced several talented dharma students-cum-translators who subsequently entered mainstream academia and now hold chairs at these research institutions. Their research and instruction, coupled with greater access for fieldwork in China, has expanded the range of Tibetan research from Oriental studies and philology to religious studies, history, anthropology, cultural studies, comparative literature, and the social sciences. Grassroots activism in the 1990s also may have presented Tibet as a possible field of study in the minds of young students. ${ }^{19}$ The Dalai Lama as a charismatic religious leader of Tibet also is conducive to the development.

The growth in Tibet-related publishing is evident. From 2000 through 2005, 98 monographs were published, accounting for 3.6 percent of the Chinese studies monograph output in the six years. No publications appeared in 2000 and 2001. In 2002, 2 titles related to description of and travel to Tibet were published. However, 2003 saw an increase in monograph publishing, to an annual output of 29 titles, more than 6 percent of the total monographic output in Chinese studies that year, second to the yearly output of

Table 4. Subjects areas Routledge published on China, Japan, and Korea 2000-2005

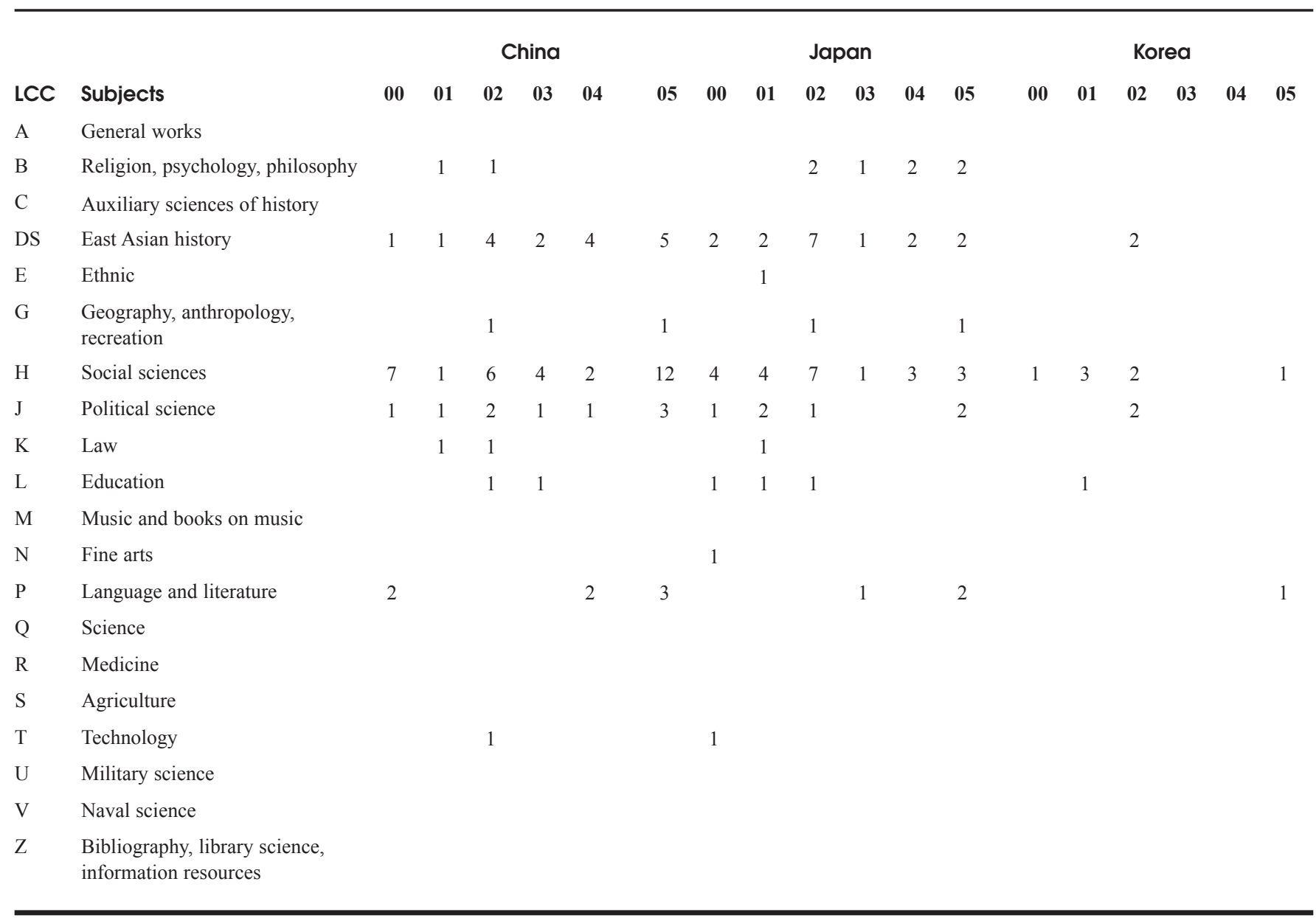


39 titles produced in 2004. In 2005, 28 titles were published, accounting for nearly 6 percent of the output of monograph publishing on Chinese studies that year. According to YBP categories, 41 of the 98 works were research level books, 25 titles were supplementary, and 31 titles were basic. Various publishers participated in the Tibetan publishing. Snow Lion published 17 titles, followed by Shambhala, which produced 13 titles. Brill of Netherlands produced 3, the University of California Press produced 2, and the Oxford University Press and the University of Washington Press each produced 1 . The number of subject areas was not as diverse as that of the larger field of Chinese studies. Of the 98 titles, 45 titles were on religion, 28 on history, 10 on fine arts, 5 on language and literature, 3 on social science, 2 each on education and geography, 1 each on science and technology, and 1 related to America. Of the 45 religious titles, 42 titles were on Buddhism. In recent years, publishing in the field of Tibetan studies centered on the subject areas of religion, history, and fine arts, particularly on religion.

\section{Conclusion}

The findings have provided information on the general output of English-language monographs of East Asian studies and on specific countries, on the productivity of university presses and commercial publishers, on the concentrations of subject areas, and on the changes over the six years examined. The study also looked at trends of research in East Asian studies. It not only sheds light on the publishing trends, but also helps in understanding the development of East Asian studies as a field.

This study is not without limitations, however. GOBI was not exhaustive. The data selected from GOBI did not include every English-language monograph published in the field of East Asian studies. Moreover, in the sampled data, some publishers may have published the same monograph under a different name. These publications are duplicates, just with different titles. Thus, the authors inadvertently may have included some instances of duplicates.

Nonetheless, these findings are significant for both scholars and librarians. The results summarized here provide an analysis and overview of what has been published and how the field of East Asian studies has evolved in recent years. This can help those concerned with the field make informed decisions regarding scholarly research and collection development. In particular, understanding publishing trends in relation to institutional and library priorities can help inform budget allocations for collections and approvalplan profile revision. For example, traditionally, East Asian studies collections in many library systems fall within the broader heading or organizational division of Arts and Humanities. These collections are more heavily weighted in the areas of arts and humanities, and budget allocations usually correlate to that division, particularly in small- to medium-sized libraries. Inviting re-evaluation of such division, the findings presented in the paper can help library decision-makers not only avoid the possibilities of some pertinent publications being missed, but also to rethink policies and practices to better meet user needs associated with growing interests in other programs, such as social sciences. In addition, this study can serve as a model for research into publishing trends and patterns of other subject areas and academic disciplines.

\section{References and Notes}

1. Frederick W. Mote, "NOTES: Recent Publication in Taiwan," Journal of Asian Studies 17, no.4 (1958): 595-606.

2. Ibid., 595 .

3. Ibid.

4. Association of American Publishers, "Industry Statistics," www .publishers.org/industry/index.cfm (accessed June 24, 2006).

5. Asian Research Trends: A Humanities and Social Science Review (Tokyo: Centre for East Asian Cultural Studies, 1991-2003).

6. N. Gerald Barrier, India and America: American Publishing on India, 1930-1985 (New Delhi: American Institute of Indian Studies, 1986).

7. Japan Foundation, "Publications," www.jpf.go.jp/e/publish/ index.html (accessed June 24, 2006).

8. Helen Hardacre, The Postwar Development of Japanese Studies in the United States (Boston: Brill, 1998).

9. Andrew D. Marble, "Special Issue: The State of the China Studies Field," Issues \& Studies 38/39, no. 4 (2002/2003): $1-10$.

10. "The Future of Korean Studies in the United States," sponsored by the Center for Korean Studies at University of California at Berkeley, May 7-8, 2001, http://ieas.berkeley .edu/events/2001.05.07-08.html (accessed June 24, 2006).

11. Mote, "NOTES."

12. James Chu-Yu Soong, "Chinese Publications in Early 1973," Journal of Asian Studies 33 no. 2 (1973): 289-93.

13. Committee on East Asian Libraries Executive Group of the Association of Asian Studies, "East Asian Collections: A Report on Current Trends Written as Part of the Association of Research Libraries' Project: Scholarship, Research Libraries, and Foreign Publishing in the 1990s," Committee on East Asian Libraries Bulletin 100 (1993): 88-109.

14. Ibid., 89 .

15. Susan D. Blum, "Margins and Centers: A Decade of Publishing on China's Ethnic Minorities," Journal of Asian Studies 61 no. 4, no. 1 (2002): 1287-1310.

16. Frank Joseph Shulman, "Doctoral Dissertations Concerned with Library and Information Science, Publishing, and Books: An Annotated Bibliography of Studies Relating to East Asia Completed between 1999 and 2004," Journal of East Asian Libraries 134 (2004): 1-28.

17. Shirley Leung, Kylie Chan, and Lisa Song, "Publishing Trends in Chinese Medicine and Related Subjects Documented in 
WorldCat," Health Information and Libraries Journal 23, no.1 (2006): 13-22.

18. Information about YBP business practices and GOBI coverage provided by Robert Nardini, then senior bibliographer at YBP, at the time data were collected.

19. Lauren Hartley, Tibetan studies librarian, C. V. Starr East Asian Library, Columbia University, New York, conversation with Chengzhi Wang, Apr. 7, 2007; see also chapter six in Donald S. Lopez, Prisoners of Shangri-la (Chicago: Univ. of Chicago Pr., 1998) for further information on the development of Tibetan Studies in the United States. 